Article history

Received Okt 17, 2019

Accepted Jul 23, 2020

\title{
Peningkatan Keterampilan Remaja Dengan Pelatihan Perbaikan PC Untuk Siswa SMKN2 Banjarmasin
}

\author{
Muhammad Hasbi ${ }^{1}$, Murdjani $^{2}$, Achmad Gufrans ${ }^{3}$, Akbar Ela Heka \\ Teknik Mesin, Politeknik Negeri Banjarmasin ${ }^{1,2,3,4}$ \\ $\underline{\text { hasbi@poliban.ac.id }}$, $\underline{\text { murdjani@poliban.ac.id }}$, gufrans@poliban.ac.id ${ }^{3,}$ akbar@poliban.ac.id
}

\begin{abstract}
Computers have been widely used in the community, because computers can ease human work. To operate it, you need special knowledge about computers to be able to run it properly. Although computers make human work easier, computers can also be damaged or error. Only some people can repair computers like computer technicians. Therefore, on this occasion we had the opportunity to provide training on how to assemble computers and repair them. With expertise in assembling and repairing computers, the community can also open up jobs that would certainly have a positive impact on the surrounding community.

Computer users / Personal Computers (PC) have been found in various circles, one of them is SMKN2 students. But many computer uses (PC) do not know how to repair a computer in case of damage, not to mention a few technicians or computer experts who can be easily found. Because of this, damage to the computer will be a difficult problem to deal with. Although there are very few technicians that we can find, repairing or servicing computers requires quite expensive costs. On this occasion, we intend to hold community service in the form of PC technician training (Personal Computer) for SMA/SMK students who aim to provide understanding and skills in making repairs, assembling, and upgrading PCs with community service programs in the form of this training. Besides this training is not limited to the provision of theory, but combined with practice so that not only knowledge is given, but the skills and creativity that are honed in this training. Outcomes of this training are skills training services and publications in national service journals.
\end{abstract}

Keywords: PC Technician Training, Community Service 


\begin{abstract}
ABSTRAK
Komputer sudah banyak digunakan di kalangan masyarakat, dikarenakan komputer dapat meringankan pekerjaan manusia. Untuk mengoperasikan nya, diperlukan pengetahuan khusus tentang komputer untuk dapat menjalankannya dengan baik. Walaupun komputer membuat pekerjaan manusia menjadi lebih mudah, komputer juga bisa rusak atau error. Hanya sebagian orang yang bisa memperbaiki komputer seperti teknisi komputer. Oleh karena itu, pada kesempatan kali ini kami berkesempatan untuk memberikan pelatihan tentang bagaimana cara merakit komputer maupun memperbaiki nya. Dengan keahlian dalam merakit maupun memperbaiki komputer, masyarakat juga dapat membuka lapangan pekerjaan yang tentu nya akan berdampak positif bagi masyarakat disekitar.

Pengguna komputer / Personal Computer (PC) sudah banyak ditemukan diberbagai kalangan, salah satunya para pelajar remaja SMK/SMA. Tetapi banyak penggunaan komputer (PC) yang tidak tau cara memperbaiki komputer jika terjadi kerusakan, belum lagi sedikit teknisi atau ahli komputer yang dapat dengan mudah ditemui. Dikarenakan hal tersebut, kerusakan pada komputer akan menjadi masalah yang sulit untuk dihadapi. Walaupun ada sedikit teknisi yang dapat kita jumpai, memperbaiki atau servis komputer memerlukan biaya yang cukup mahal. Pada kesempatan kali ini, kami berkeinginan mengadakan pengabdian masyarakat berupa pelatihan teknisi PC (Personal Computer) kepada pelajar remaja SMK/SMA yang bertujuan untuk memberikan pemahaman dan keterampilan dalam melakukan perbaikan, merakit, maupun upgrade PC dengan program pengabdian masyarakat berupa pelatihan ini. Selain itu pelatihan ini tidak sebatas pemberian teori, melainkan gabungan dengan praktek sehingga bukan hanya pengetahuan saja yang diberikan, namun keterampilan dan kreatifitas yang diasah dalam pelatihan ini. Target luaran dari pelatihan ini adalah jasa pelatihan keterampilan dan publikasi dalam jurnal pengabdian nasional.
\end{abstract}

Kata Kunci: Pelatihan Teknisi PC, Pengabdian Masyarakat 


\section{PENDAHULUAN}

Pelaksanaan kegiatan pengabdian ini mendapat dukungan dari P3M Poliban dan sumber dana dari DIPA Poliban, sangatlah membantu dalam proses pelaksanaan pengabdian masyarakat ini. Pengabdian masyarakat ini bermitra dengan SMKN2 Banjarmasin sekaligus peserta nya yaitu siswa-siswi SMKN2 Banjarmasin. Pihak sekolah memilih peserta yang memiliki minat dan antusias yang tinggi, sehingga diharapkan peserta bersemangat dalam mengikuti kegiatan pelatihan ini nantinya sampai diakhir pertemuan.

\section{Permasalahan Mitra:}

Penggunaan komputer dikalangan remaja SMA/SMK banyak digunakan untuk mengetik, membuat laporan, browsing internet, bermain game, dll. Hal ini tidak diikuti dengan pemahaman dan keterampilan dalam mengatasi masalah yang terjadi pada komputer, seperti misalnya jika PC (Personal Computer) mengalami kerusakan ataupun gangguan. Sehingga, ketika komputer rusak atau error, Hal ini tidak bisa diatasi dengan sendirinya, dikarenakan tidak ada keahlian dalam memperbaiki komputer. Dan juga di perlukan biaya yang tidak sedikit saat memperbaiki ke tempat servis. Oleh karena itu, berdasarkan hal-hal diatas, yaitu kurangnya pemahaman dan keterampilan pada kalangan remaja dalam memperbaiki komputer. Pengabdian masyarakat ini memberikan pelatihan teknisi PC untuk remaja SMA/SMK.

\section{Tujuan dan Manfaat Kegiatan:}

Adapun kegiatan pengabdian masyarakat ini bertujuan untuk memberi beberapa manfaat bagi siswa SMKN2 Banjarmasin diantaranya:

- Menambah pengetahuan dasar tentang komponen utama untuk merakit PC dan juga memilih spesifikasi yang tepat sesuai dengan keperluan pengguna.

- Meningkatkan keterampilan siswa dalam memperbaiki, merakit, dan juga upgrade komponen PC dengan benar

\section{METODE KEGIATAN}

Metode pelaksanaan yang digunakan dalam pelatihan ini adalah metode gabungan antara teori dan praktek, dimana peserta tidak hanya mendapatkan materi, tetapi juga dapat mempraktekan langsung materi yang sudah disampaikan oleh instruktur. Berikut rincian kegiatan yang berlangsung selama kegiatan :

Tabel 1: Rincian Kegiatan Pelatihan

\begin{tabular}{|l|l|l|l|}
\hline No. & \multicolumn{1}{|c|}{ Kegiatan Pelatihan } & \multicolumn{1}{c|}{ Metode } & \multicolumn{1}{c|}{ Kegiatan Peserta } \\
\hline 1. & Mempelajari hardware dan software & Penyampaian teori & Menyimak materi \\
\hline 2. & $\begin{array}{l}\text { Mempelajari komponen utama yang } \\
\text { membangun suatu sistem PC }\end{array}$ & $\begin{array}{l}\text { Penyampaian teori dan } \\
\text { menunjukkan komponen }\end{array}$ & $\begin{array}{l}\text { Menyimak materi dan } \\
\text { memperhatikan } \\
\text { komponen secara } \\
\text { langsung }\end{array}$ \\
\hline
\end{tabular}




\begin{tabular}{|l|l|l|l|}
\hline 3. & $\begin{array}{l}\text { Mengenal jenis dan fungsi komponen } \\
\text { pada mainboard PC }\end{array}$ & $\begin{array}{l}\text { Penjelasan nama } \\
\text { komponen pada } \\
\text { mainboard beserta } \\
\text { fungsinya }\end{array}$ & $\begin{array}{l}\text { Menyimak materi dan } \\
\text { memperhatikan } \\
\text { komponen secara } \\
\text { langsung. }\end{array}$ \\
\hline 4. & $\begin{array}{l}\text { Mempelajari berbagai kabel data dan } \\
\text { kabel power pada PC }\end{array}$ & $\begin{array}{l}\text { Penyampaian teori dan } \\
\text { menunjukkan komponen. }\end{array}$ & $\begin{array}{l}\text { Menyimak materi dan } \\
\text { memperhatikan } \\
\text { komponen secara } \\
\text { langsung. }\end{array}$ \\
\hline 5. & $\begin{array}{l}\text { Praktek membongkar/melepas } \\
\text { komponen pada PC }\end{array}$ & Teori dan Praktek & $\begin{array}{l}\text { Melakukan praktek } \\
\text { membongkar dengan } \\
\text { urutan yang benar. }\end{array}$ \\
\hline 6. & $\begin{array}{l}\text { Praktek merakit komponen PC } \\
\text { Telakukan praktek } \\
\text { merakit komponen PC } \\
\text { dengan urutan yang } \\
\text { benar. }\end{array}$ \\
\hline 7. & $\begin{array}{l}\text { Praktek mempartisi hardisk dan } \\
\text { menginstal sistem operasi }\end{array}$ & $\begin{array}{l}\text { Melakukan praktek } \\
\text { menginstal OS. }\end{array}$ \\
\hline
\end{tabular}

\section{HASIL DAN PEMBAHASAN}

Pelatihan ini memberikan wawasan dan pemahaman kepada peserta. Untuk dapat melihat perbedaan hasil dan pemahaman peserta, diperlukan adanya test sebelum dan sesudah pelatihan. Tes sebelum pelatihan dinamakan PreTest dan sesudah pelatihan dinamakan PostTest. Hal ini bertujuan untuk melihat seberapa jauh pemahaman peserta sesudah pelatihan, apakah peserta memahami materi yang disampaikan, tidak memahami materi, ataupun malah membuat bingung peserta.

Berikut hasil penilaian terhadap dua jenis tes tersebut:

Tabel 2: Penilaian Peserta Pelatihan

\begin{tabular}{|c|l|c|c|c|}
\hline \multirow{2}{*}{ No. } & \multicolumn{1}{|}{ Nama Peserta } & \multirow{2}{*}{ Kelas \& Jurusan } & \multicolumn{2}{|c|}{ Hasil Tes } \\
\cline { 3 - 4 } & & & Pre Test & Post Test \\
\hline 1 & M. Putra Aditya Madani & X TKJ A & 45 & 60 \\
\hline 2 & Mutia Rahmah & X TKJ A & 60 & 95 \\
\hline 3 & Hayati Safriani & X TKJ B & 50 & 65 \\
\hline 4 & Muhammad Rahul & X TKJ C & 40 & 60 \\
\hline 5 & Risna Oktaviani & X TKJ C & 55 & 88 \\
\hline 6 & M. Rieko Aprilianto & X RPL B & 65 & 88 \\
\hline 7 & M. Azhim Nugroho & X RPL B & 60 & 90 \\
\hline 8 & Reza Revaldi & X RPL B & 60 & 78 \\
\hline 9 & Muhammad Luthfi & X RPL B & 55 & 65 \\
\hline 10 & Asa Zeliq Pratama & X RPL B & 60 & 88 \\
\hline 11 & Hilman & X RPL B & 58 & 78 \\
\hline 12 & Saiful Rahman & X RPL B & 65 & 88 \\
\hline
\end{tabular}

Dari kedua hasil tes diatas dapat disimpulkan bahwa, nilai peserta meningkat sesudah pelatihan yang berarti peserta dapat memahami teori dan praktek yang diberikan oleh instruktur pada saat pelatihan. 


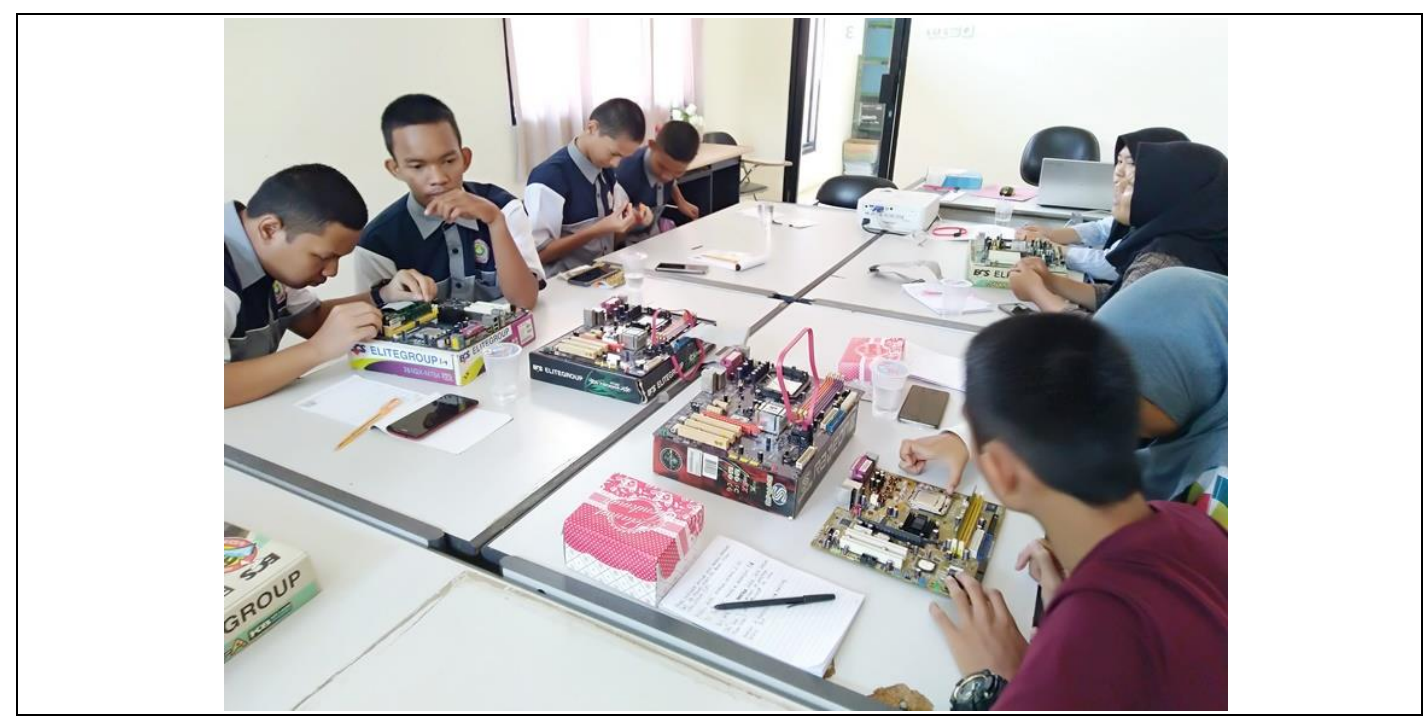

Gambar 1: Mengenal komponen pada mainboard

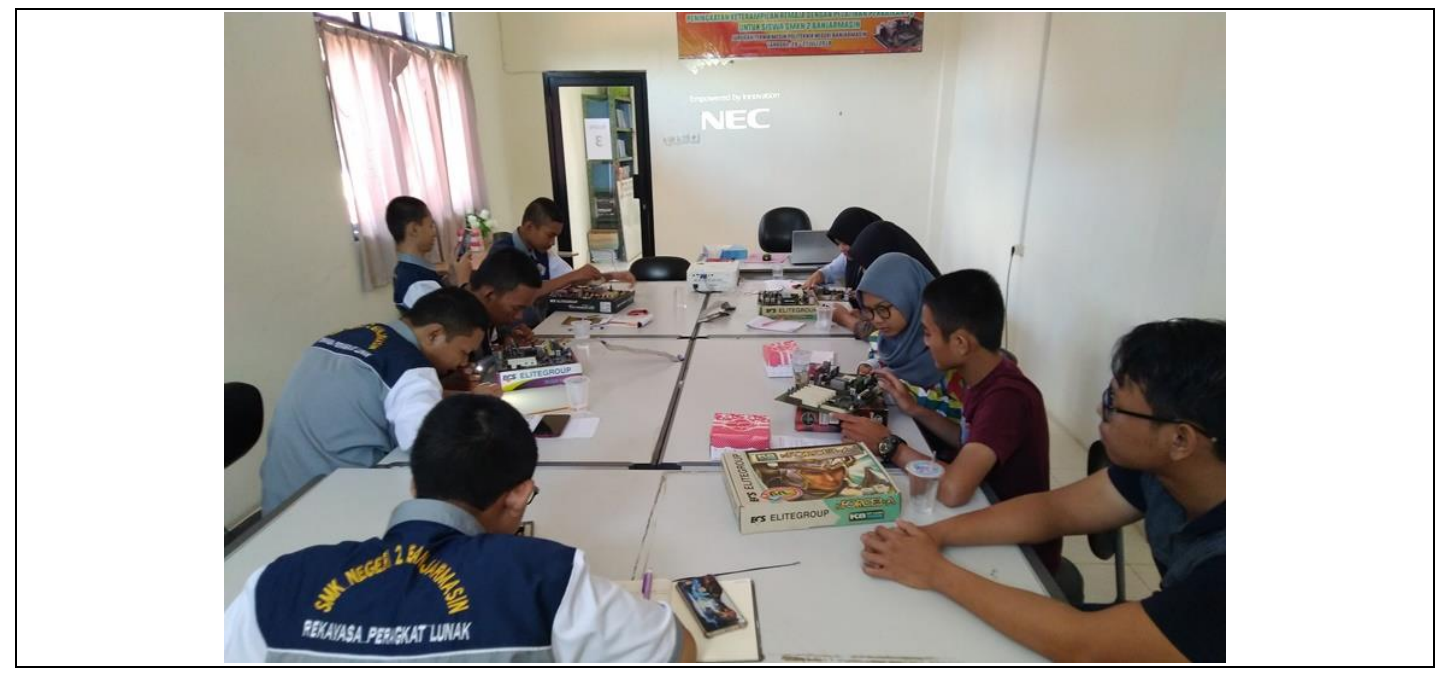

Gambar 2: Praktek merakit komponen pada mainboard

\section{KESIMPULAN}

Dalam kegiatan ini peserta dapat mengikuti arahan teori dan praktek yang diberikan oleh instruktur dengan baik, dari pengenalan teori dasar sampai praktikum merakit komponen PC. Meskipun ada beberapa kendala yang dihadapi oleh peserta seperti kesalahan pemasangan kabel, hal ini adalah hal yang wajar pada saat proses pembelajaran. Dampak positif dari pelatihan ini bagi peserta, Selain mendapatkan wawasan dan keterampilan dalam memperbaiki, merakit dan upgrade PC, peserta juga dapat membuka lapangan pekerjaan sebagi teknisi PC yang mana akan sangat berguna bagi masyarakat maupun peserta itu sendiri. 


\section{UCAPAN TERIMA KASIH}

Ucapan terimakasih kami ucapkan kepada unit P3M Poliban dan kampus kami tercinta Politeknik Negeri Banjarmasin, atas dukungan dana dan kesempatan yang diberikan sehingga kegiatan ini dapat berjalan dengan baik sesuai dengan yang diharapkan. Semoga dengan terlaksananya kegiatan ini maka hubungan akan terjalin dengan baik antara pihak kampus dengan masyarakat sekitarnya.

\section{DAFTAR PUSTAKA}

Panduan Pelaksanaan Penelitian dan Pengabdian Pada Masyarakat di Perguruan Tinggi Edisi XII Tahun 2018. Direktorat Riset dan Pengabdian Pada Masyarakat, Direktorat Jenderal Penguatan Riset dan Pengembangan, Kementerian Riset, Teknologi dan Pendidikan Tinggi.

Rencana Strategis Pengabdian Kepada Masyarakat Politeknik Negeri Banjarmasin Tahun 2017-2021.

A. Hermansyah, "Buku Panduan Merakit Komputer”, Filla Press, 2011

Suyitno,"Pelatihan Komputer Bagi Perangkat Desa dan Karang Taruna di Purworejo", Laporan Pengabdian Masyarakat, 2018. 